\title{
OVIPOSITION PREFERENCE AND DEVELOPMENT OF RICE WEEVIL, SITOPHILUS ORYZAE (LIN.) (COLEOPTERA: CURCULIONIDAE) IN DIFFERENT STORED GRAINS
}

\author{
Masuma Akhter, Shanjida Sultana, Tangin Akter and Shefali Begum* \\ Department of Zoology, University of Dhaka, Dhaka-1000, Bangladesh
}

\begin{abstract}
Oviposition preference and development of rice weevil, Sitophilus oryzae (Coleoptera: Curculionidae) were observed in three varieties of stored grains i.e. parboiled rice (Oryza sativa), wheat (Triticum aestivum) and pulse (Cicer arietinum). In no choice tests, the mean number of eggs laid were $360.3 \pm 2.60$ in rice, $382 \pm$ 2.49 in wheat and $394 \pm 2.06$ in pulse. In case of choice tests, the mean number of eggs laid were $13.6 \pm 0.4$ in rice, $14.2 \pm 0.37$ in wheat and $15.6 \pm 0.4$ in pulse The differences between the number of eggs laid in rice, wheat and pulse varied significantly in both no-choice and choice tests. The respective incubation period, larval and pupal period of the weevil reared on rice, wheat and pulse were $5.7 \pm$ $0.27,5 \pm 0.47$ and $5.4 \pm 0.27$ days, respectively, $21 \pm 0.47,20.3 \pm 0.27,19 \pm 0.47$ days, respectively and $10.3 \pm 0.27,10.7 \pm 0.27,11.3 \pm 0.27$ days, respectively. The total development time from egg to adult recorded in rice, wheat and pulse was 37 $\pm 0.47,36 \pm 0.47$ and $35.6 \pm 0.72$ days, respectively. The difference between the larval periods was significant $(\mathrm{p}<0.05)$ when they reared in wheat and pulse. The larval and pupal period varied significantly $(\mathrm{p}<0.05)$ between the individuals reared in rice and pulse. The developmental period was shorter in pulse than in rice and wheat.
\end{abstract}

Key words: Oviposition, preference, development, rice weevil, stored grains

\section{INTRODUCTION}

Cereals are the staple and nutritive food, but their storage is not safe due to the infestation of certain stored grain insect pests. So, there is an urge to protect them safely from qualitative and quantitative loss that can result from environmental conditions favored feeding by microbes, insects, mites and rodents (Mohale et al. 2010). It is estimated that about 35\% of crops all over the world are destroyed by pests (Yevoor 2003). Stored grain insect pest can cause reductions in weight, quality, commercial value and seed viability. It has been estimated by Vina et al. (1997) that 70 per cent of these insects are Coleopterans and the most damaging species of storage insects are from the genera Sitophilus and Trilobium (Pinto et al. 1997). In Bangladesh, 19 insect species have been recorded so far from stored grain (Alam 1971), out of which Sitophilus oryzae (Linn.) is considered to be the most common pest in all types of stored grains of Bangladesh. They are major pest of cereals like rice, sorghum, wheat, barley and

*Author for corresponding: <shefali@du.ac.bd>. 
maize both in field before harvest and in storage. Sitophilus oryzae L. (Coleoptera: Curculionidae) commonly called rice weevil has become primary pest of stored grains of warm climatic areas. They cause damage to grains that are stored at $25-30^{\circ} \mathrm{C}$ and at low relative humidity as these conditions favored the development of this pest (Batta 2004). Rice weevil, a ubiquitous pest of economic importance, is an internal feeding insect that bores into stored grain. Adult weevils feed mainly on the endosperm, reducing the carbohydrate content and the larvae feed preferentially on the germ of the grain, thus removing a large percentage of the protein and vitamins. Additionally, the kernel damage caused by $S$. oryzae larvae enables other species, the external feeders, which are not capable of infesting sound grains, so increase the damage rapidly. According to Alam (1971), 5 - 8\% of the food grains, seeds and different stored products are lost annually due to storage pests.

The influences of factors such as seed species, variety, age and moisture content and environmental temperature and relative humidity have been shown to influence Sitophilus oviposition (Kanaujja and Levinson 1981, Urrelo and Wright 1989). Sitophilus spp. have also been reported to prefer large seeds for oviposition; large seed were more likely to be parasitized or contain more than one egg than smaller seeds (Stejskal and Kucerova 1996). Zakladnoi and Ratanova (1987) reported that during the development period of weevils the larvae consume about $50 \%$ of the total weight of grain. Germinating capacity of the seed is also lowered in severely infested grains and grains infested by weevils become more susceptible to infestation by other associated pests like grain beetles and mites. This huge amount of loss could be associated with their biology because their all four larval stages and pupal stage occur inside the grain. Therefore, their control and elimination in storage is very difficult. Their biology has been reviewed widely by many authors (Longstaff 1981, Bhuiyan et al. 1990). The present study was conducted to gain information on oviposition preference and development of rice weevil that will be of great value towards the process to protect grains in a better way and to derive all its advantage.

\section{MATERIAL AND METHODS}

Studies on the life cycle and oviposition preference of Sitophilus oryzae (L.) on three different stored grains rice, pulse and wheat were conducted during 2013-14 in the Entomology laboratory, Department of Zoology, University of Dhaka. This investigation was carried out within an incubator set at temperature $27 \pm 4^{\circ} \mathrm{C}$ and $70 \pm 4 \%$ relative humidity (rh). These temperature and rh were selected because they were reported to be most favorable conditions for population growth of weevil (Longstaff 1981). 
Rice weevil was collected from the stored rice of Shamsun Nahar Hall Dining Mess, University of Dhaka. The weevils were identified by following Alam (1971), Metcalf and Flint (1962), and Halstead (1963). The weevils were sexed under the microscope by means of their rostrum characteristics and abdomen deflection (Tombes 1971, Lum and Baker 1975). Three different types of grains i.e. parboiled rice (Oryza sativa), pulse (Cicer arietinum) and wheat (Triticum aestivum) were collected from local grain stores of Dhaka city. Any cracked or damaged grains were removed. Any extraneous materials, if found were also removed to get only fresh grains as test samples. All grains were sterilized at $-18^{\circ} \mathrm{C}$ for two weeks in a freezer. After the treatment, the grains were spread on normal white papers at room temperature $28 \pm 4^{\circ} \mathrm{C}$ and $70 \pm 4 \%$ rh for 24 hours to bring them to normal temperature and kept in sealed containers before they were used.

Stock culture of the rice weevil, Sitophilus oryzae was maintained in an incubator at $27 \pm 4^{\circ} \mathrm{C}$ and $70 \pm 4 \%$ rh to ensure their regular supply for tests throughout the experimental period. The mass rearing medium was parboiled rice. Stock cultures were maintained in five large Petri dishes (10" diameter). Each Petri dish was filled with approximately equal quantities (300 g) of rice grains. Fifty pairs of adult rice weevils were released into each of five Petri dishes for oviposition. A wet cotton ball was kept regularly within the Petri dishes to maintain the moisture. After 48 hours of oviposition, the adult weevils were completely sieved out from each Petri dish using a $1.5 \mathrm{~mm}$ sieve. The metabolic wastes and intervals cleared regularly to avoid grain dampness and microbial growth. Experiments were started to conduct with the insects emerged from the second generation of the rearing $S$. oryzae and so on.

For no choice test, 100 grains (not cracked or broken) from each type (Rice, Pulse, Wheat) were kept in separate Petri dishes (5" diameter). Five pairs of newly emerged adults of age group $24-48$ hrs were released in each Petri dish. The Petri dishes were kept in incubator at $27 \pm 4^{\circ} \mathrm{C}$ and $70 \pm 4 \% \mathrm{rh}$. Released insects were allowed to oviposit for three days. Similar test was continued for five times using the same insects. After each test the grains were collected and the grains containing eggs were separated out by examining with magnifying glass and the number of eggs laid were counted. The experiment was replicated five times.

For choice test, 50 grains (not cracked or broken) from each type (Rice, Pulse, Wheat) were kept together in one Petri dish (5" diameter). Five pairs of newly emerged adults of age group $24-48 \mathrm{hrs}$ were released in the Petri dish. The Petri dish were kept in incubator at $27 \pm 4^{\circ} \mathrm{C}$ and $70 \pm 4 \% \mathrm{rh}$. Released insects were allowed to oviposit for three days. After three days, the grains were 
collected and the grains containing eggs were separated out by examining with magnifying glass and the number of eggs laid were counted. The experiment was replicated five times.

To study the life cycle of rice weevil Sitophilus oryzae (L.) 100 grains (not cracked or broken) from each different type of grains (Rice, Wheat and Pulse) were kept in Petri dishes. Ten pairs (male and female) of newly emerged adults of age group $24-48 \mathrm{hrs}$ were released in each Petri dish. There were five such replications for each variety that were marked as Rep.-1, Rep.-2 and Rep.-3 and so on. The Petri dishes were kept in incubator at temperature $27+4^{\circ} \mathrm{C}$ and $70 \pm$ $4 \% \mathrm{rh}$. Weevils were kept for two days to oviposit. Damaged grains were replaced regularly with uninfested grains. Grains containing eggs were separated out by examining under microscope and were used for further study. The grains (rice, wheat, pulse) on which the rice weevils laid eggs were transferred into another sets of Petri dishes ( 3 " diameter). To determine the incubation period 10 grains were dissected with a pair of forceps under the microscope from the day of oviposition to egg hatching. Thus, incubation period was recorded. The remaining seeds were used for the determination of larval- and pupal period. On hatching the larvae of rice weevil were allowed to feed individually inside the grains in Petri dish. Five grains per day were dissected with a pair of forceps to see the larval period. The dissection of grains was continued until they attained the pupal stage. The period between egg hatching and pupation was observed as larval period. Within the infested grains when the larvae attained the pupal stage the seeds were allowed as such until adult emergence. The period between formations of pupae till the adult emergence was noted as pupal period.

Standard deviation, standard error and t test were calculated. For evaluating relative effectiveness of life cycle and oviposition of rice weevil on different type of grains, the experimental data were subjected to ANOVA.

\section{RESULTS AND DISCUSSION}

In case of no choice test the total number of eggs laid by Sitophilus oryzae was $360.3 \pm 2.60$ in rice, $382 \pm 2.49$ in wheat and $394 \pm 2.06$ in pulse. The total number of eggs laid by Sitophilus oryzae in choice test was $13.6 \pm 0.4$ in rice, $14.2 \pm 0.37$ in wheat and $15.6 \pm 0.4$ in pulse. The number of eggs laid by Sitophilus oryzae in rice, wheat and pulse varied significantly $(\mathrm{p}<0.05)$ for both choice and no choice tests (Tables 1 and 2).

The present results have conclusively demonstrated that rice weevil Sitophilus oryzae prefers pulse and large seeds for oviposition than rice and wheat under no choice- and choice condition. Similar findings were reported by Stejskel and Kucerova (1996) who found Sitophilus spp. prefer large seeds for 
oviposition; large seed were more likely to be parasitized or contain more than one egg than smaller seeds. Salunkhe and Jadhav (1982) observed a positive correlation between oviposition and seed surface, seed with smooth surface being preferred than those with rough and spiny ones. Teotia and Singh (1968) observed that the weevil seemed to be guided in its oviposition preference by certain other factors besides the texture of the seed coat. The egg laying power of the weevil increased when the preferred seeds for oviposition were provided. Russell (1968) observed that some weevil preferred to lay in large size grains. He also noticed that, relative hardness of the grain of various sorghum varieties was a dominant factor in affecting the oviposition rates. In this experiment it was seen that the pulse was quite considerably larger in size than that of the other grains and the adults preferred to lay maximum number of eggs on pulse.

Table 1. Number of eggs laid in rice, wheat and pulse in no choice test

\begin{tabular}{lcccc}
\hline Grain & $\begin{array}{c}\text { No. of observation } \\
(\mathrm{n})\end{array}$ & $\begin{array}{c}\text { No. of } \\
\text { seeds }\end{array}$ & $\begin{array}{c}\text { Weevil released } \\
\text { (Pair) }\end{array}$ & $\begin{array}{c}\text { Total no. of eggs laid } \\
(\mathrm{M} \pm \mathrm{SE} \text { ) }\end{array}$ \\
\hline Rice & 5 & 100 & 5 & $360.3 \pm 2.60 \mathrm{a}$ \\
Wheat & 5 & 100 & 5 & $382.0 \pm 2.49 \mathrm{~b}$ \\
Pulse & 5 & 100 & 5 & $394.0 \pm 2.06 \mathrm{c}$ \\
\hline
\end{tabular}

Column followed by the different letters varied significantly

Table 2. Number of eggs laid in rice, wheat and pulse in choice test

\begin{tabular}{lcccc}
\hline Grain & $\begin{array}{c}\text { No. of observation } \\
(\mathrm{n})\end{array}$ & $\begin{array}{c}\text { No. of } \\
\text { seeds }\end{array}$ & $\begin{array}{c}\text { Weevil released } \\
\text { (Pair) }\end{array}$ & $\begin{array}{c}\text { Total no. of eggs laid } \\
(\mathrm{M} \pm \mathrm{SE})\end{array}$ \\
\hline Rice & 5 & 50 & 5 & $13.6 \pm 0.40 \mathrm{a}$ \\
Wheat & 5 & 50 & 5 & $14.2 \pm 0.37 \mathrm{~b}$ \\
Pulse & 5 & 50 & 5 & $15.6 \pm 0.40 \mathrm{c}$ \\
\hline
\end{tabular}

Column followed by the different letters varied significantly.

The development of rice weevil, Sitophilus oryzae (L.) comprised of four definite stages, such as egg, larva, pupa and adult in all the three different stored products is shown in Table 3.

Incubation period: Eggs were laid inside the cavity in the grains of rice, wheat and pulse. Incubation period was with a mean of $5.7 \pm 0.27$ days in rice, $5 \pm$ 0.47 days in wheat and $5.4 \pm 0.27$ days in pulse. The incubation period of rice weevil did not significantly vary between rice, wheat and pulse $(\mathrm{p}<0.05)$. The result is comparable with Anon. (1934) who recorded that the eggs of S. oryzae laid on maize hatched in five to six days after oviposition. 
Larva: Larval development took place inside the grain. Larval period was with a mean of $21 \pm 0.47$ days in rice, $20.3 \pm 0.27$ days in wheat and $19 \pm 0.47$ days in pulse. The findings are comparable with Lin (1958) who recorded the larval period of 15 to 29 days with an average of 19.20 days on stored rice. The larval period varied significantly between the individuals reared in rice and pulse and between wheat and pulse (Student's t- test; $\mathrm{p}<0.05$ ).

Table 3. Development period of Sitophilus oryzae in different stored grains (rice, wheat and pulse)

\begin{tabular}{lccccccc}
\hline Grain & $\begin{array}{c}\text { No. of } \\
\text { obs. } \\
\text { (n) }\end{array}$ & $\begin{array}{c}\text { No. of } \\
\text { seeds }\end{array}$ & $\begin{array}{c}\text { Weevil } \\
\text { released } \\
\text { (Pair) }\end{array}$ & $\begin{array}{c}\text { Incubation } \\
\text { period } \\
\text { (Mean } \pm \text { SE) } \\
\text { (Day) }\end{array}$ & $\begin{array}{c}\text { Larval period } \\
\text { (Mean } \pm \text { SE) } \\
\text { (Day) }\end{array}$ & $\begin{array}{c}\text { Pupal period } \\
\text { (Mean } \pm \text { SE) } \\
\text { (Day) }\end{array}$ & $\begin{array}{c}\text { Total duration } \\
\text { (Mean } \pm \text { SE) } \\
\text { (Egg to adult) } \\
\text { (Day) }\end{array}$ \\
\hline Rice & 5 & 100 & 10 & $5.7 \pm 0.27$ & $21.0 \pm 0.47$ & $10.3 \pm 0.27$ & $37.0 \pm 0.47$ \\
Wheat & 5 & 100 & 10 & $5.0 \pm 0.47$ & $20.3 \pm 0.27$ & $10.7 \pm 0.27$ & $36.0 \pm 0.47$ \\
Pulse & 5 & 100 & 10 & $5.4 \pm 0.27$ & $19.0 \pm 0.47$ & $11.3 \pm 0.27$ & $35.6 \pm 0.72$ \\
\hline
\end{tabular}

Pupa: Pupation took place in larval tunnel. Pupal period was with a mean of $10.3 \pm 0.27$ days in rice, $10.7 \pm 0.27$ days in wheat and $11.3 \pm 0.27$ days in pulse. We can compare the findings with Bheemanna (1986) who recorded pupal period ranged from 8 to 11 days on $\mathrm{CSH}-5$ sorghum genotypes. The pupal period varied significantly between the individuals reared in rice and pulse (Student's ttest; $\mathrm{p}<0.05$ ).

Total duration: Total duration from egg to adult was with a mean of $37 \pm 0.47$ days in rice, $36 \pm 0.47$ days in wheat and $35.6 \pm 0.72$ days in pulse. The findings are in agreement with Howe (1952) who reported 21 to 46 days of life cycle of rice weevil. In this experiment, it was observed that the development was faster in pulse then on rice and wheat. Reddy et al. (2002) observed that weevil emergence was earlier in normal boiled wheat; this was because of the more favorable moisture content of normal wheat.

Teotia and Singh (1968) observed that in general, the development of the larvae was better on seeds which were preferred by the weevil for oviposition. The bigger the size of the host seeds the larger were the weevils produced. The similar result also observed in the present study where Sitophilus oryzae prefer pulse for oviposition and developmental period also shorter in pulse.

From the present study, it may be concluded that the rice weevil, Sitophilus oryzae preferred pulse more to oviposit than rice and wheat. Oviposition increased with the increase of the adult age. The development of Sitophilus oryzae was quicker in pulse than in rice and wheat. 


\section{LITERATURE CITED}

ALAM, M.Z. 1971. Pest of stored grains and other products and their control. The agricultural information service. 3 R. K. Mission Road, Dacca-3. 61 pp.

ANONYMOUS, 1934. Entomological and Zoological investigations. Report of South Carolina Experimental Station 47: 56-64.

BATTA, Y.A. 2004. Control of rice weevil (Sitophilus oryzae L.) (Coleoptera: Curculionidae) with various formulations of Metarhizium anisopliae. Crop Prot. 23: 103-108.

BHEEMANNA, M. 1986. Studies on biology of rice weevil Sitophilus oryzae Linnaeus (Curculionidae: Coleptera) and host resistance in sorghum. M. Sc. (Agri.) Thesis, University of Agricultural Sciences, Dharwad.

BHUIYAN, MD. I.M., ISLAM, N., BEGUM, A. and KARIM, M.A. 1990. Biology of the rice weevil, Sitophilus oryzae (L.). B. J. Zool. 18: 67-73.

HALSTEAD, D. G. H. 1963. External sex differences in stored products Coleoptera. Bull. Entomol. Res. 54: 119-134.

HOWE, R. W., 1952. The biology of rice weevil, Calandra oryzae (L.). Ann. Appl. Biol. 39: 168-180.

KANAUJIA, K. R. and LEVINSON, H. Z. 1981. Phagostimulatory responses and oviposition behavior of Sitophilus oryzae (L.) to newly harvested and stored wheat grains. Z. Argl. Entomol. 91: 417 424.

LONGSTAFF, B.C. 1981. Biology of the grain pest species of the genus Sitophilus (Coleoptera: Curculionidae): A critical review. Pro. Eco. 3: 83-130.

LUM, P.T.M. and BAKER, J.E. 1975. Sexual dimorphism in the sixth abdominal sternite of Sitophilus oryzae (L.) (Coleoptera: Curculionidae). Stored Pro. Res. 11: 57-59.

METCALF, C.L. and FLINT, W.P. 1962. Destructive and useful insects. McGraw Hill Book Co. Fourth edition. $1087 \mathrm{pp}$.

MOHAlE, S., Allotey, J. and SIAME, B.A. 2010. Control of Tribolium confusum J. Du val by diatomaceous earth (protect- ittm) on stored groundnut (Arachos hypogaea) and Aspergillus flavus link spore dispersal. Afr. J. Food Agri. Nutr. Develop. 10(6): 2678-2694.

PINTO, Jr A.R., FURIATTI, R.S., PEREIRA, P.V.S. and LAZZARI, F.A. 1997. Avaliacåo de Insecticidas no control de Sitophilus oryzae (L.) (Coleoptera: Curculionidae), e Rhyzopertha dominica (Fab.) (Coleoptera: Bostrichidae) em Arroz Armazenado Anais da Sociedade Entomologica do Brasil. 26: 285-290.

REDDY, K. P.K., SINGH, P.U. and REDDY, K.D. 2002. Sorghum resistance to the rice weevil, S. oryzae (L.): Antixenosis Sci. Appli. 22: 1-19.

RUSSELL, M.P. 1968. Influence of rice variety on oviposition and Development of the rice weevil, $S$. oryzae, and the maize weevil, S. zeamais. Ann. Entomol. Soc. Amer. 61(5): 1335-1336.

SALUNKHE, R. and JADHAV, S. 1982. Weight loss of stored wheat caused by insect feeding. J. Econ. Entomol. 46: 609- 610.

STEJSKAL, V. AND KUCEROVA Z. 1996. The effect of grain size on the biology of Sitophilus granarius (L.) (Coleoptera: Curculionidae). I. Oviposition, distribution of eggs and adult emergence. J. Appl. Entomol. 120: 143- 146.

TEOTIA, T.P.S. and SINGH, V.S. 1968. On the oviposition behaviour and development of Sitophilus oryzae (L.) in various natural foods. Indian J. Entomol. 30: 119-124.

TOMBES, A. S. 1971. Sexual dimorphism in Sitophilus granarius (L.) as viewed under the scanning electron microscope. Canadian J. Zool. 49: 579-580.

URRELO, R. and WRIGHT, V.F. 1989. Oviposition performance of Sitophilus zeamais Motsch. (Coleoptera: Curculionidae) on resistant and susceptible maize accessions. J. Kans. Entomol. Soc. 62: 23- 31. 
VINA UELA, E., ADAN, A., DEL ESTAL, P., MARCO, V. and BUDIA, F. 1997. Plagas de los products Almace- na- dos. H. D. Madrid, EspanÄ. 20: 93-109.

YEVOOR 2003. Biology and management of rice weevil, Sitophilus oryzae (Linn.) in maize grains. $M$. Sc. (Agri.) Thesis, University of Agricultural Sciences, Dharwad.

ZAKLADNOI, G.A. and RATANOVA, V.F. 1987. Stored-Grain Pests And Their Control. New Delhi, Oxonian Press Pvt. Ltd. 268 pp.

(Manuscript received on 02 October 2017; revised on 31 December 2017) 